\title{
Uso de Ferramenta como Instrumento no Processo de Ensino-Aprendizagem
}

\author{
Graziella Simeão Munhoz ${ }^{1}$, Andréa Cintra Lopes² \\ ${ }^{1}$ Mestrado em Ciências - Área: Processos e Distúrbios da Comunicação, Faculdade de Odontologia de Bauru \\ da Universidade de São Paulo (FOB-USP) \\ ${ }^{2}$ Professora Associada do Departamento de Fonoaudiologia da Faculdade de Odontologia de Bauru da \\ Universidade de São Paulo
}

* Autora para correspondência: aclopes@usp.br

\section{RESUMO}

Relatamos neste artigo o uso e a aplicação de uma ferramenta desenvolvida com o objetivo de acompanhar a aprendizagem, a evolução e a complexidade dos casos atendidos pelos alunos do terceiro ano de graduação do curso de Fonoaudiologia no Estágio Clínico da Disciplina de Diagnóstico Audiológico, oferecida pelo Departamento de Fonoaudiologia da Universidade de São Paulo, campus Bauru. A proposta do uso da avaliação somativa por meio da ferramenta formulário Controle dos Atendimentos: Clínica de Diagnóstico Audiológico no estágio clínico no terceiro ano busca auxiliar o professor na atribuição de notas, fornecer feedback ao estudante, comparar os resultados obtidos com diferentes graduandos e verificar a condução dos atendimentos, além de permitir ao docente acesso aos exames e às condutas audiológicas tomadas em cada caso.

Palavras-Chave: Educação; Aprendizagem; Novas Tecnologias; Avaliação.

\begin{abstract}
In this article we report the use and application of a tool developed with the objective of accompanying the learning, evolution and complexity of the cases attended by the students of the 3rd year of the Speech Pathology course in the Clinical Stage of the Audiological Diagnosis Discipline offered by the Department of Audiology and speech pathology at the University of São Paulo, Bauru city. The proposal of the use of summative evaluation through the tool "Control of care: Audiological diagnosis clinic" in the clinical stage in the 3rd year seeks to assist the teacher in the assignment of notes; providing feedback to the student, comparing the results obtained with different students and verifying the conduct of the consultations, besides allowing the teacher access to the audiological examinations and conducts taken in each case.
\end{abstract}

Keywords: Education; Learning; New Technologies; Evaluation.

\section{Introdução}

As tecnologias de comunicação e informação (TICs) estão cada vez mais presentes em nosso meio, o que levou a mudanças no ensino em todos as etapas e ciclos da vida. Atualmente, milhares de informações estão disponíveis em apenas um toque no computador e nos smartphones. Nesse cenário, o professor, que teve sua aprendizagem baseada em um modelo tradicional, precisa buscar ferramentas para se aproximar dessa geração de novos educandos.

De acordo com Avancini, Conti e Gouveia (2011), há ferramentas disponíveis e educadores que podem usá-las de um modo ou de outro. Desde 1997, o MEG incentiva o uso de TICs, com a criação do programa Pro-Info - Programa Nacional de Informática na Educação, por meio da incorporação da tecnologia como ferramenta adicional à prática pedagógica em diferentes áreas de conhecimento.

A literatura aponta o uso de TICs como um fator positivo que deve ser estimulado e que pode ser determinante no processo de aprendizagem (LAGUARDIA, PORTELA\&VASCONGELOS, 2007), assim como para o melhor entrosamento no ambiente de aprendizagem (ASSMANN, 2000). 
Evangelista e Menezes (2017) identificaram, por meio de uma revisão de literatura, que a inserção de novas metodologias que utilizam as TICs é possível e extremamente positiva para o aluno no seu processo de aprendizagem. No entanto, tal processo traz desafios ao docente, uma vez que o modelo vivenciado ainda tem muito da escola tradicional.

O desenvolvimento de habilidades e competências para um diagnóstico eficiente faz parte da formação do fonoaudiólogo. A aprendizagem significativa para o estudante de fonoaudiologia está na maneira como eles interagem com o paciente e seus familiares, mediante as entrevistas e a realização dos diversos testes e procedimentos para a avaliação do sistema auditivo. Muitas dessas habilidades e atitudes são treinadas. Nesse contexto, a atuação na Clínica-Escola (ou serviço -escola) é essencial na formação dos graduandos, e envolve um encontro semanal entre estudantes, professores e pacientes.

Este relato descreve a experiência da utilização de uma ferramenta desenvolvida com o objetivo de acompanhar a aprendizagem, a evolução e a complexidade dos casos atendidos pelos alunos do terceiro ano de graduação do curso de Fonoaudiologia no Estágio Clínico da Disciplina de Diagnóstico Audiológico, oferecida pelo Departamento de Fonoaudiologia da Faculdade de Odontologia da Universidade de São Paulo, campus Bauru - FOB-USP.

Compreendendo que a forma por meio da qual se avalia é crucial para o processo de ensino e aprendizagem, muitas formas de avaliação são propostas para as atividades clínicas, e constituem um desafio para os professores repensar suas práticas avaliativas e inseri-las na formação dos profissionais da saúde. Parte-se da compreensão de que a avaliação envolve a ideia de reflexão acerca dos conhecimentos já construídos e estabelecidos.

Sendo assim, a avaliação sinaliza aos alunos a trajetória do seu processo formativo. A avaliação assume a função de indicador para orientar a prática educacional, para mostrar aos professores e alunos o que será necessário ajustar no processo de aprendizagem. Nesse contexto, a avaliação não é realizada em um momento específico, e sim ao longo de todo o processo acadêmico.

De acordo com Cunha (2009), há um consenso quanto à compreensão de que a aprendizagem mais importante é aquela que vai além da mera aquisição de informações. A autora, em seu estudo de revisão, verificou o aparecimento de novos meios de ensino, novos métodos de aprendizagem, novas tecnologias e até novas práticas avaliativas. No entanto, relatou que ainda não existe o mesmo entendimento no que se refere à questão de conceber a avaliação como uma aliada da aprendizagem, em favor do aluno.

Na visão de Villas Boas (2004), a avaliação que promove a aprendizagem do aluno e do professor é denominada de formativa. Não se avalia para atribuir nota, conceito ou menção e, sim, para se conhecer o que o aluno já aprendeu e o que ele ainda não aprendeu e, dessa forma, providenciar os meios para que ele aprenda. $\mathrm{O}$ autor apontou as seguintes características da avaliação formativa:

a) É conduzida pelo professor;

b) Destina-se a promover a aprendizagem;

c) Leva em conta o progresso individual, o esforço nele colocado e outros aspectos não especificados no currículo;

d) São considerados vários momentos e situações em que capacidades e ideias que, na avaliação somativa, poderiam ser classificados como erros, na formativa, fornecem informações diagnósticas;

e) Os alunos exercem papel central, devendo atuar em sua própria aprendizagem, ativamente, ou seja, eles progredirão se compreenderem suas possibilidades e fragilidades e se souberem como se relacionar com elas.

Nesse contexto, o uso da TICs na avaliação do aluno permite que o professor realize avaliações instantâneas ou o acompanhamento do processo de aprendizagem ao longo do processo.

O método de avaliação somativa é relevante no conjunto das práticas pedagógicas no processo de ensino e aprendizagem (OLIVEIRA, 2012). De acordo com Aranha (1993), tal procedimento 
aparece no final do processo, e pretende avaliar o produto, ou seja, não constitui a base de trabalho, que é a principal preocupação, quer de orientadores, quer de estagiários. Ela permite classificar o estagiário, atribuindo-lhe uma nota final. Contudo, ela não deve ser confundida com classificação, e sim ser o reflexo do conjunto de um trabalho referente ao aperfeiçoamento do processo e à consequente melhoria do produto. A avaliação somativa nos possibilita comparar os objetivos definidos com os atingidos (produto), refletindo sobre o (in)sucesso do processo de estágio.

Nesse sentido, ela compreende um balanço final de toda a atividade desenvolvida ao longo do processo de ensino, ou, neste caso, do processo de estágio (ARANHA, 1993).

Esse instrumento de avaliação também serve como uma amostragem do que foi ensinado e aprendido, verificando o quanto os alunos incorporaram dos objetivos propostos e fornecendo informações que permitem que o estudante passe ou não para o próximo nível. Além disso, a avaliação somativa atende a uma demanda da sociedade que pede provas documentais de aprendizado (OLIVEIRA, 2012).

A avaliação somativa estabelece balanços confiáveis dos resultados obtidos ao final de um processo de ensino-aprendizagem, destacando a coleta de informações e a elaboração de instrumentos que possibilitam medir os conhecimentos a serem avaliados. Tal metodologia de avaliação tem por finalidade corresponder à função social de assegurar que as características dos estudantes respondam às exigências do sistema, assim como também pode ter uma função formativa de saber se os alunos adquiriram os comportamentos previstos pelos professores e, como consequência, observar os pré-requisitos necessários para aprendizagens posteriores ou para determinar os aspectos que deveriam ser modificados em uma futura repetição da mesma sequência de ensino -aprendizagem (JORBA \& SANMARITI, 2003).

Progressivamente se fazem necessárias mudanças na prática educativa, e, para isso, é preciso mudar a prática da avaliação, ou seja, mudar sua finalidade e como se avalia, segundo Jorba e Sanmariti (2003).

A proposta do uso da avaliação somativa por meio da ferramenta formulário "Controle dos Atendimentos: Clínica de Diagnóstico Audiológico", no estágio clínico no terceiro ano, busca auxiliar o professor na atribuição de notas, fornecer feedback ao estudante, comparar os resultados obtidos com diferentes estudantes e verificar a condução dos atendimentos, além de permitir ao docente acesso aos exames e às condutas audiológicas tomadas em cada caso.

O formulário compreende questões a serem respondidas obrigatoriamente, sendo em campo para marcação ou para digitar. As informações contidas são: data do atendimento, estudante(s) (quem atendeu o caso em questão), nome do paciente, RG (número do prontuário do paciente), data de nascimento, procedimentos realizados, diagnóstico audiológico, próximo atendimento (o que o estudante fará na semana seguinte). Participam desse procedimento de marcação no formulário apenas o docente responsável (Figura 1).

A realização da avaliação somativa por meio do formulário permite ao docente perceber o progresso do estudante qualitativa e quantitativamente. Em vista disso, o método em questão pode auxiliar na hora de se verificar o quanto aquele estágio produziu em números de procedimentos realizados, por meio dos dados obtidos numericamente, tal como o perfil dos casos atendidos, e assim ajudar na hora da elaboração da prova teórico-prática, além de servir como banco de dados (Figura 2).

A utilização da ferramenta auxilia a condução do estágio clínico, além de ajudar o docente a deixar os dados registrados, podendo ser usados na hora de fornecer o feedback ao estudante, acompanhar a evolução e a complexidade dos casos atendidos. Da mesma forma, o estudante pode observar sua evolução, erros, acertos, grau de dificuldade.

Essa ferramenta possibilita ao professor acompanhar o perfil de cada estágio pelo qual é responsável, seja quanto às características clínicas que esse grupo de estudantes atende, seja quanto 


\begin{tabular}{|c|c|}
\hline Controle dos atendimentos: Clínica & $\square$ Imitanciometria \\
\hline de Diagnóstico Audiológico & $\square$ Mascaramento \\
\hline $\begin{array}{c}\text { Professor (a) responsável: Dra. Andréa Cintra Lopes } \\
\text { Grupo 03: mannâa }\end{array}$ & $\square$ Orientação ao paciente. \\
\hline *obrigatório & $\square$ Outro: \\
\hline Data do atendimento * & Diagnóstico audiológico * \\
\hline DD MM AAAA & Sua resposta \\
\hline I / 2018 & \\
\hline Aluno * & Conduta * \\
\hline Angélica & Sua resposta \\
\hline Augusto & \\
\hline Franciele & Próximo atendimento \\
\hline Isabella & Caso novo \\
\hline Priscila & Dar continuidade ao atendimento anterior \\
\hline & Avaliação teórico- prática \\
\hline Dados do paciente: Nome * & Outro: \\
\hline Sua resposta & Informacõec relevantec * \\
\hline & Sua resposta \\
\hline Data de nascimento * & \\
\hline DD MM AAAA & Pós graduandos que acompanharam o atendimento * \\
\hline & $\square$ Graziella \\
\hline Procedimentos realizados * & $\square$ Maria Cecilia \\
\hline$\square$ Anamese audiológica & $\square$ Simone \\
\hline$\square$ Inspeção do Meato Acústico Externo - MAE & \\
\hline$\square$ Audiometria Tonal Liminar & ENVIAR \\
\hline$\square$ Logoaudiometria & nca envie senhas pelo Formulários Google. \\
\hline
\end{tabular}

Figura 1 - Formulário utilizado para avaliar o controle dos atendimentos.

\begin{tabular}{l}
$\begin{array}{l}\text { Controle dos atendimentos da Clínica de Diagnóstico Audiológico-Manhã (respostas) } \\
\text { Arquivo Editar Visualizar Inserir Formatar Dados Ferramentas Formulário Complementos Ajuda }\end{array}$ \\
\hline RG \\
\hline
\end{tabular}

Figura 2 - Banco de dados produzido a partir do formulário de controle dos atendimentos.

ao perfil do estudante em seus pontos positivos e negativos, por exemplo em tomadas de decisões. Por fim, pode-se analisar o perfil do grupo de estudantes que estão sendo avaliados, se estes são ou não pró-ativos e outros fatores que auxiliam na hora de computar a nota dos mesmos.

\section{Considerações Finais}

A avaliação do processo de ensino e aprendizagem no ensino superior requer que o educando não só adquira os conhecimentos científicos necessários para o desempenho da sua profissão, mas avalie de fato as habilidades e competências 
exigidas para tal. Assim, a avaliação deve estar articulada ao trabalho pedagógico. Nesse sentido, a modernização do ensino e novas ferramentas de tecnologia de comunicação e informação, em conjunto com outras estratégias de ensino-aprendizagem, auxiliam no rendimento do aluno, bem como no seu processo de aprendizagem.

De acordo com os alunos, o uso dessa ferramenta auxiliou a tomada de decisão e o investimento em determinados temas para o estudo individual ou em grupo, assim como a clareza no momento do feedback. Essa ferramenta vai ao encontro da realidade tecnológica deles, propiciando controle, motivação e envolvimento no processo de ensino e aprendizagem, fazendo com que os alunos participassem da necessidade de casos clínicos diversificados, com diferentes alterações no sistema auditivo e saúde geral para a construção do conhecimento. Foi positivo o uso de tal ferramenta, o que despertou interesse para ambos os lados, aluno e professor, aumentando a interação, o controle das atividades, a evolução e a descrição dos atendimentos, e, claro, o aluno sente-se responsável, importante e em total interação com seu processo de aprendizagem, uma vez que faz parte ativamente de todo o processo.

\section{Referências Bibliográficas}

ARANHA, A. C. "Orientação de Estágios Pedagógicos: Avaliação Formativa versus Avaliação Somativa". Boletim SPEF, Universidade de Trás-osMontes e Alto Douro (Assistente), n. 7/8, Inverno/ Primavera de 1993, pp. 157-165.

ASSMANN, H. "A Metamorfose do Aprender na Sociedade da Informação". Ci. Inf., Brasília, vol. 29, n. 2, ago. 2000.

AVANCINI, M; CONTE, F. \& GOUVEIA, F. "Entrevista com Pierre Lévy". ComCiência. Campinas, n. 131, 2011.

CUNHA E. M. L. "Avaliação Formativa no Ensino Superior: um Estudo Exploratório a partir da Perspectiva dos Professores". Rev Facitec, vol. 1, n. 5, 2009.

EVANGELISTA P. A. \& MENEZES L. L. "O Papel do Docente na Articulação entre as Tecnologias da Informação e Comunicação e Aprendizagem do Aluno". Revista de Graduação USP, vol. 2, n. 3, dez. 2017.

JORBA, J. \& SANMARTI, N. "A Função Pedagógica da Avaliação". Avaliação como Apoio à Aprendizagem. Porto Alegre: Artmed, 2003, pp. 23-45.

LAGUARDIA J.; PORTELA M. C. \& VASCONCELLOS M. M. "Avaliação em Ambientes Virtuais de Aprendizagem". Educ. Pesqui, São Paulo, vol. 33, n. 3, dez. 2007.

OLIVEIRA, J. "Avaliação Contínua versus Somativa". Maio, 2012. Disponível em: <https://breltchat.wordpress.com/2012/05/17/resumo-avaliacaocontinua-x-avaliacao-somativa-by-jossely-oliveira/ $>$. Acessado em 23 abr. 2015.

VILLAS BOAS, B. M. de F. Portfólio, Avaliação e Trabalho Pedagógico. 2 ed. Campinas, SP: Papirus, 2004. 